\title{
ANÁLISE BIÔNICA EM PROJETOS DE DESIGN: A FRUTA-DO-CONDE COMO REFERÊNCIA DE TEXTURA EM PISOS PARA ÁREAS EXTERNAS
}

BIONIC ANALYSIS IN DESIGN PROJECTS: THE SUGARAPPLE AS A TEXTURE REFERENCE FOR OUTDOOR FLOORING

\author{
Flávia Lopes da Silveira \\ Liliane Basso \\ Rubem Pechansky \\ Wilson Kindlein Jr.
}

\begin{abstract}
Resumo
Este estudo aborda o emprego de elementos da natureza no desenvolvimento de projetos de design. Como referência biônica foi selecionada a Annona coriacea, conhecida como fruta-do-conde. A escolha foi fundamentada na morfologia dos gomos que compõem o fruto e na estrutura de sua superfície. A metodologia utilizada incluiu a digitalização tridimensional de um espécime de Annona, o tratamento dos dados obtidos, a criação de texturas a partir desses dados e a subsequente obtenção de uma forma bidimensional. Essa forma gerou, através de modelagem computadorizada, um tipo de piso que foi ambientado em um cenário tridimensional virtual para apresentação gráfica. $O$ resultado obtido foi um piso vazado, adequado a áreas externas, que permite que o solo absorva água da chuva. O procedimento metodológico deste estudo mostrou ser adequado ao objetivo proposto e pode ser adotado em outros trabalhos que utilizem elementos da natureza como referência para o design de produtos.
\end{abstract}

Palavras-chave: Biônica; Design; Pisos para Áreas Externas.

\begin{abstract}
This paper addresses the use of natural elements in the development of design projects. The sugar-apple (Annona coriacea) was elected as the bionic reference for this study. The choice was based on the morphology of its seed-bearing carpels and on its surface quality. The methodology included the $3 d$ scanning of a specimen, followed by data processing, texture creation and the design of a two-dimensional shape. The shape was then modeled as a floor tile that was placed in a virtual $3 d$ scene and rendered. The result is a hollow floor tile which is suitable for outdoor use and allows the soil to absorb rainwater. The methodological approach used in this study proved to be adequate to its original purpose and can be adopted in other research projects that use elements of nature as references for product design.
\end{abstract}

Keywords: Bionics; Design; Outdoor Floor Tiles. 


\section{Introdução}

Segundo Broeck, biônica é o estudo dos sistemas e organizações naturais visando analisar e recuperar soluções funcionais, estruturais e formais para aplicá-las na resolução de problemas humanos através da geração de tecnologias e concepção de objetos e sistemas de objetos. Portanto, podese analisar elementos disponíveis na natureza sob aspectos de forma, estrutura, volume, encaixe e textura, entre outros. E investigar o potencial a ser explorado que melhor se adapte a uma necessidade, deficiência ou até mesmo ao aprimoramento de um projeto. Tirar proveito de mecanismos que são fruto de milhões de anos de evolução e aplicá-los na solução de problemas projetuais pode otimizar o tempo de pesquisa.

Nesse sentido, dentre os elementos naturais investigados para subsidiar a formulação prática desta pesquisa, selecionou-se a fruta-doconde (Annona coriácea), para servir de base para a elaboração de estudos técnicos, criativos e experimentais, e a partir disso desenvolver soluções de projeto. Nesta perspectiva salientam-se as formas dos gomos usados como textura, que foram os aspectos motivadores do início desta investigação. Especulou-se então que essas formas vazadas, quando aplicadas em pisos para áreas externas, poderiam auxiliar na infiltração da água da chuva, promovendo a irrigação do solo sobre o qual o piso foi assentado. A seguir foram sugeridos produtos destinados a revestimento de superfícies, os quais poderiam ser comercializados em lojas de decoração, design e arquitetura. Além disso, pôde-se perceber, através de uma pesquisa de estado da arte, que há uma carência no mercado de pisos para áreas externas que sejam atrativos esteticamente e que possuam opções de materiais não convencionais, o que motivou ainda mais as investigações.

O objetivo principal deste estudo é sugerir pisos para áreas externas que permitam a infiltração da água da chuva no solo, levando em consideração o potencial encontrado nas formas dos gomos da fruta-doconde para a criação de formatos vazados.

\section{Análise Biônica}

A analogia com elementos disponíveis na natureza pode ser uma maneira de descobrir novos princípios, formas, processos e estruturas de novos produtos. Esse processo de utilização de um elemento natural como referência para o processo criativo no design está diretamente ligado ao campo da biônica. Cabe salientar que o referencial biológico escolhido para esta pesquisa será utilizado apenas como determinante formal e estético.

Para Kindlein, biônica é uma "ciência multidisciplinar", que busca através da análise de sistemas naturais (estruturas, processos, funções e relações) e da aplicação dessas referências, solucionar problemas técnicos existentes nos produtos já concebidos.

Segundo György Doczi : 
arquitetura podem auxiliar-nos nesse esforço, visto que tais proporções constituem limitações partilhadas que criam relações harmoniosas baseadas nas diferenças. Assim, elas nos mostram que as limitações não são apenas restritivas mas também criativas. (DOCZI, 1990)

Conforme Bonsiepe, a análise biônica de fenômenos formais da natureza facilita e estimula a capacidade de percepção de detalhes e princípios presentes em sua estrutura.

Importantes e inovadoras ideias vêm surgindo de pesquisas sobre sistemas e propriedades naturais. $O$ trem bala Shinkansen desenvolvido pelo engenheiro Eiji Nakatsu é um exemplo. O estudo de caso é apresentado pelo Instituto de Biomimética de Missoula, Estados Unidos. O projeto tem como referência o bico do pássaro Martim-Pescador (mergulha sem espirrar água em busca de sua refeição). Visando solucionar um dos grandes problemas do trem bala que é a vibração e o barulho, o engenheiro buscou inspiração no formato do bico deste pássaro. $\mathrm{O}$ trem-bala atual viaja $10 \%$ mais rápido e consome $15 \%$ menos energia, e ainda a pressão do ar foi reduzida em $30 \%$ em relação ao modelo anterior.

Outro exemplo de aplicação Biônica é o estudo feito sobre a coloração da Morpho Borboleta apresentado por Rossin. Através da pesquisa, descobriu-se que a cor da borboleta é criada pela refração da luz e não pela presença de pigmento. Copiando as camadas de proteína presente nas escamas das asas da borboleta é possível, através da refração de luz, criar cores. Este mesmo processo poderia ser aplicado em tecidos, paredes, superfícies, reduzindo consumo de energia e problemas de desbotamento.

\section{Modelo Biológico Escolhido}

A Annona coriacea (figura 1) é uma espécie da família das anonáceas (Annonaceae), primeiramente catalogada por Martius e conhecida popularmente no Brasil como fruta-do-conde ou araticum. Seus frutos são compostos, comestíveis e em forma de gomo ou baga. Essa formação em gomos foi um dos fatores determinantes na escolha da Annona como ponto de partida para este trabalho.

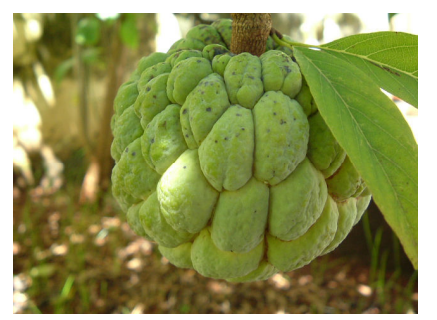

Figura 1. Annona coriacea. Fonte: Wikimedia Commons

A escolha da fruta-do-conde como modelo biológico para o desenvolvimento de um revestimento se deu por conta do potencial encontrado em sua morfologia. Aspectos do nascimento, crescimento, 
distribuição e proporção dos gomos do fruto são elementos que foram explorados na geração experimental de novas formas. O módulo resultante da geometrização e parametrização obtido através do processo de digitalização da fruta-do-conde foi aplicado como elemento de revestimento para áreas externas.

\section{Design de Superfície}

As possibilidades oriundas do desenvolvimento da tecnologia vêm ampliando as alternativas no campo do design de superfície. Hoje já se pensa em "estruturas gráficas espaciais com propriedades visuais, táteis, funcionais e simbólicas" que definem e constroem espaços. Estas características constituem a superfície como próprio objeto, e não mais somente como elemento de aplicação a um plano. A proposta de pisos para áreas externas apresentada neste estudo é conduzida sob a ótica destas características (superfície-objeto), onde as alternativas formais resultantes do referencial biológico são traduzidas em novas configurações de pisos.

Para Rubim, "todos os objetos, sobretudo os produtos criados pela civilização industrial, têm superfície. É para diferenciá-los, entre si e entre todos, que a superfície merece identidade. De preferência, única".

Dentre as áreas onde o design de superfície atua podemos citar os revestimentos cerâmicos para paredes e pisos que, segundo Rütschilling, representam um importante campo de aplicação do design de superfície.

No entanto, ao se trabalhar com revestimentos cerâmicos é importante considerar fatores como: técnicas de produção, materiais, texturas, cores e principalmente a composição das placas, ou seja, a maneira como se arranja os elementos sobre o fundo.

Para Cardoso et al, "é fundamental que o profissional tenha domínio sobre os efeitos causados na composição, além dos elementos próprios da linguagem visual que caracterizam o produto".

Concomitantemente às pesquisas bibliográficas, buscou-se fazer um sucinto levantamento ilustrativo de pisos disponíveis na indústria que possuam algum tipo de inovação de superfície e forma (relevos, rebaixos, encaixes, composições ou módulos) inspiradas em elementos naturais (figura 2). Este levantamento tem como objetivo apenas obter referências de mercado. A fonte utilizada foi a Expo Revestir, que, segundo dados disponíveis no site oficial do evento, é a maior feira de revestimentos da América Latina e a quarta maior do setor no mundo. 


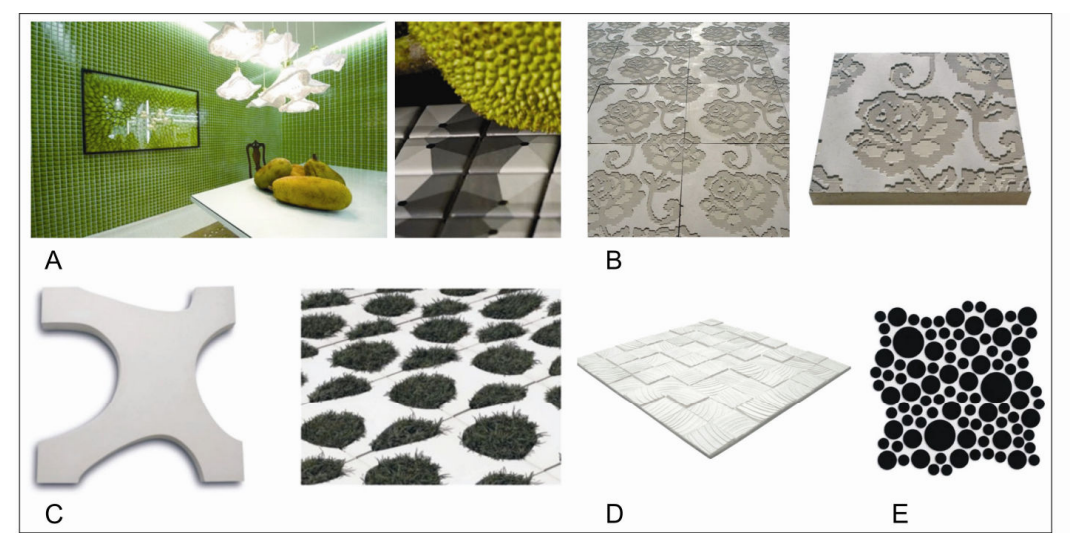

Figura 2. Modelos de pisos disponíveis no mercado: (A) Coleção Bico de Jaca, da Jatobá - Marcelo Rosenbaum, (B) Piso em concreto produzido em máquina CNC - Jethro Macey, (C) Coleção da Marca Solarium - Renata Rubim, (D) Linha Craft, da Solarium Heloísa Crocco, (E) Piso Astral Nero - Mosarte.

Este panorama industrial reforça o princípio de que é possível, através de referências naturais, conceber novas idéias e contribuir de forma efetiva com o design de superfície.

\section{Metodologia}

A metodologia adotada neste trabalho inclui a digitalização tridimensional de um espécime de fruta-do-conde, tratamento dos dados obtidos, testes em materiais, criação de textura, modelagem tridimensional dos pisos e renderização final.

\subsection{Digitalização Tridimensional}

A primeira etapa consistiu na digitalização de um espécime de fruta-doconde através do scanner 3D do LdSM-UFRGS (figura 3), o que permitiu obter um alto grau de precisão dos detalhes da superfície. O conjunto de dados obtidos por esse processo é chamado nuvem de pontos.

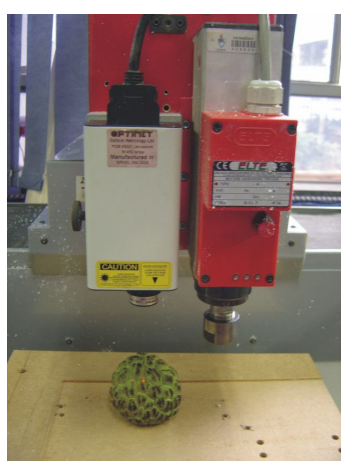




\subsection{Tratamento dos Dados}

A seguir, a nuvem de pontos foi editada e montada no software Geomagic, especializado na criação de modelos tridimensionais a partir de dados digitalizados. Em seguida foi feita a escolha de três vistas (topo, base e lateral) (figura 4) para testes posteriores. Esses dados serviram para a geração dos caminhos de ferramenta CNC no ArtCAM, software especializado em usinagem para controle numérico computadorizado.

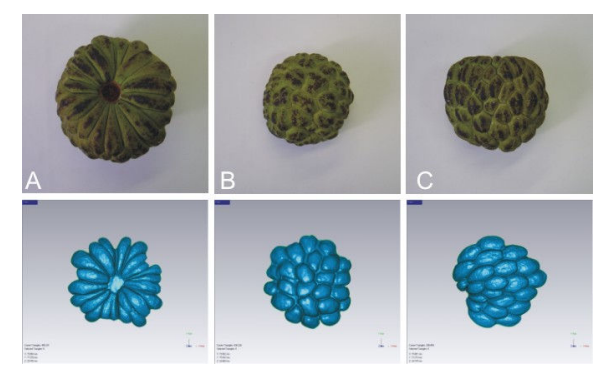

Figura 4. Nuvem de pontos editada a partir da digitalização da fruta-do-conde. Vista (A) de base, (B) lateral e (C) topo.

\subsection{Testes em Materiais}

A partir dos dados tratados foram feitos testes em alto-relevo, baixo-relevo e vazado em diversos tipos de materiais. Os testes práticos em materiais se deram através de usinagem CNC (executados no LdSM-UFRGS) (figura 5) em alginato de sódio (A), resina epóxi Cibatu (B), gipsita (C) e madeira (D). A usinagem dos materiais foi feita com as ferramentas PMG 720 e PMG 710. As madeiras escolhidas foram a sucupira (Pterodon emarginatus) e a peroba (Aspidosperma spruceanum). Foi também realizada uma série de cortes a laser em papel na empresa Atelier do Marketing, de Porto Alegre, exibindo tanto os módulos isolados quanto os repetidos e vazados, em versões positiva e negativa.

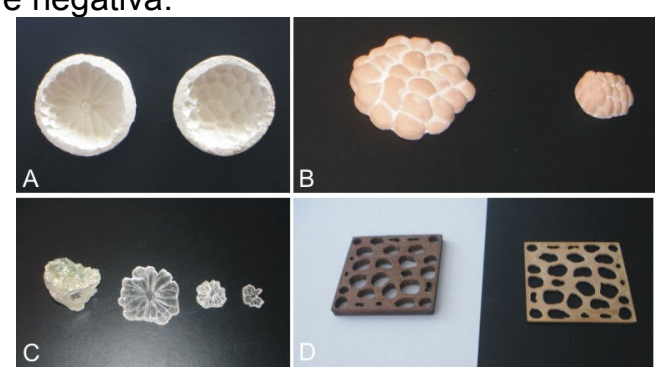

Figura 5. Usinagem CNC do modelo em alginato de sódio (A), resina epóxi (B), gipsita (C) e madeira (D). (LdSM). 
Os testes feitos a partir das formas vazadas resultaram em um simples módulo capaz de gerar superfícies contínuas. Isso sugeriu a aplicação desse módulo em revestimentos de superfícies.

\subsection{Criação da Textura}

O módulo da vista de base da fruta-do-conde foi convertido para o Xara Xtreme Pro 5, um editor de desenhos vetoriais comercial.

O comando feather (suavização) foi usado então para a criação de uma imagem com transições suaves entre dois planos, evitando o "efeito escada" que aconteceria se a imagem não fosse tratada. A imagem foi exportada em formato PNG para o IrfanView, um visualizador de imagens que utiliza os mesmos algoritmos de tratamento de imagem de softwares comerciais como o Photoshop (figura 6). Nele foi realizado um ajuste de brilho que transformou o preto original da imagem em cinza-claro, para evitar um efeito acentuado demais na textura. A seguir a imagem foi negativada e exportada para formato TGA (figura 7).

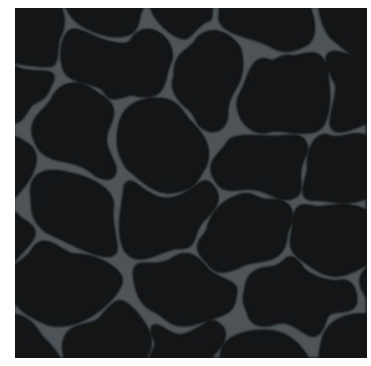

Figura 6. Imagem exportada em formato PNG para o IrfanView.

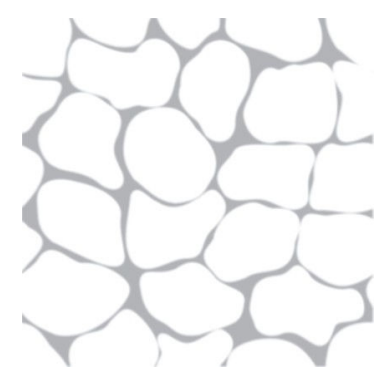

Figura 7. Imagem negativada e exportada para formato TGA.

\subsection{Modelagem Tridimensional dos Pisos}

Foi utilizado como ponto de partida o módulo único obtido através da vista de base da fruta-do-conde (figura 8) (A). Para a realização do desenho com as curvas originais em 2D (B) foi utilizado o CorelDRAW. Para a conversão 
do desenho para 3D foi utilizado o Xara Xtreme Pro, onde foi criado um quadrado circunscrito às formas originais $(C)$.

Através de múltiplas aplicações das três operações geométricas planas (translação, escala e rotação) a área ocupada foi ampliada (D). Para preenchimento mais uniforme da área, foram realizadas novas aplicações das operações geométricas e o acréscimo de novas formas exibidas em vermelho na figura $(E)$. As curvas $(F)$ foram então transformadas em segmentos de reta e exportadas para formato EPS.
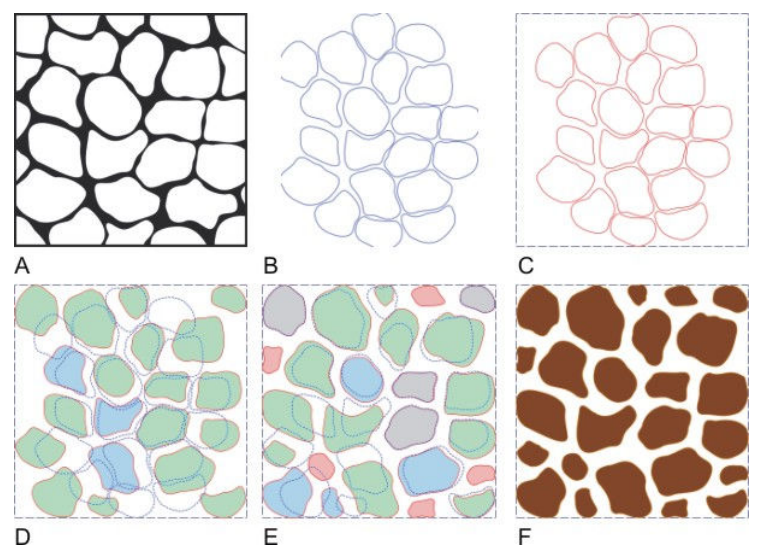

Figura 8. Processo de modelagem tridimensional do piso.

Para o modelo em 3D do piso tipo 1, primeiramente foi utilizado o recurso de suavização de sólidos do Wings3D, um modelador disponível gratuitamente. $\mathrm{O}$ arquivo EPS obtido no Xara Xtreme Pro foi importado no formato Adobe Illustrator (figura 9) (A). Em face mode foram selecionados todos os polígonos e aplicado o comando smooth, o que arredondou todas as formas (B). $\mathrm{O}$ arquivo foi então exportado para o formato nativo do 3D Studio (3ds).

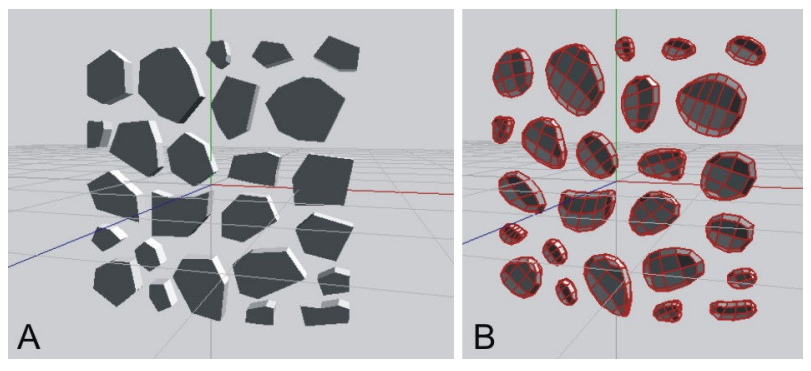

Figura 9. Suavização e arredondamento da forma.

Para o restante das operações em 3D foi utilizado o trueSpace, um software profissional que foi disponibilizado como freeware em 2008. Nele foi acrescentado um plano (figura 10) (A) e realizada uma intersecção entre o plano e o sólido, o que criou um novo objeto plano no qual foi realizada 
uma operação de extrusão (sweep) que gerou um objeto com espessura (B). A seguir, foi criado um novo paralelepípedo circunscrevendo essa nova forma. Uma operação de subtração booleana gerou um novo objeto com 25 furos poligonais, no qual foi aplicado o comando bevel duas vezes para a suavização das bordas (C), o que diminui a espessura aparente entre as paredes e melhora o aspecto do objeto ao ser renderizado. Finalmente, foi aplicado um material com cor semelhante à cerâmica (figura 11) (A) e feito um bump mapping com a textura TGA obtida na etapa anterior (B).
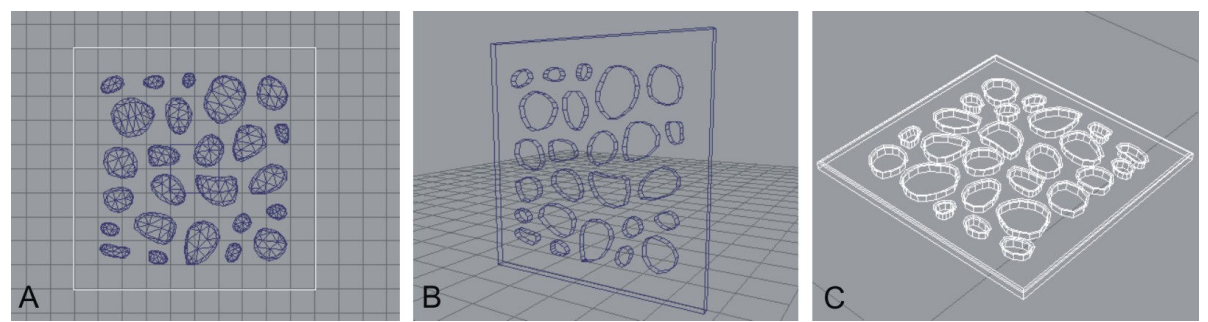

Figura 10. Operações 3D que antecedem a aplicação do material no modelo.
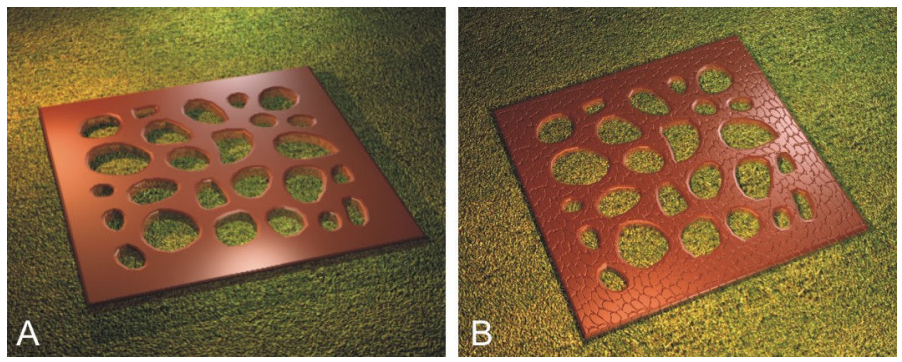

Figura 11. Aplicação de material e textura no modelo 3D do Piso tipo 1.

Para o segundo piso (tipo 2) o processo foi praticamente o mesmo, com a diferença que o ponto de partida foi o módulo contínuo obtido com a vista de base da fruta-do-conde (figura 12) em vez do módulo único. Nesse modelo foi usado o Inkscape, outro editor vetorial (gratuito), para suprir a falta do comando insert new nodes no Xara Xtreme Pro. O material escolhido dessa vez foi o alumínio (figura 13). O motivo pelo qual foi utilizado um metal para este piso é que nas cerâmicas a resistência à tração é relativamente baixa comparada com a resistência à compressão. A geometria deste piso faz com que ele precise suportar tanto esforços de tração quanto de compressão, e isso é inerente à maioria dos metais de uso industrial. O alumínio foi escolhido porque um piso externo de materiais ferrosos não garantiria imunidade contra as intempéries. 


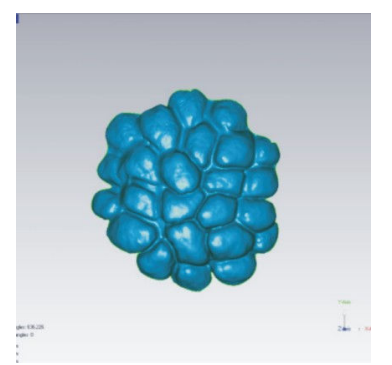

Figura 12. Vista de base da fruta-do-conde.

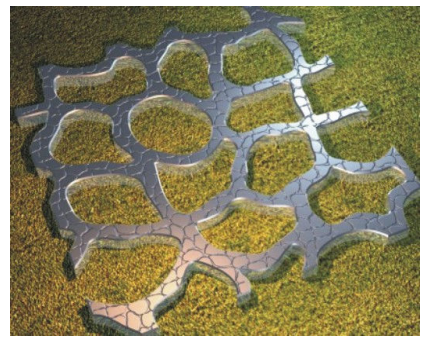

Figura 13. Piso tipo 2 em alumínio.

Foi realizado um cálculo simplificado do custo do material que seria gasto para os dois modelos de pisos. Nesse cálculo foi levado em consideração somente o custos dos materiais, não tendo sido incluídos os valores de produção, criação ou mão de obra.

\subsection{Renderização Final}

Para a criação da cena final, foi criada uma simples casa à qual foram acrescentados alguns modelos prontos (cadeiras, banco, guarda-sol, plantas) obtidos gratuitamente nos sites trueSpace Community Forums e The3dStudio.com, para dar um contexto mais realista à cena final (figura 14). As texturas naturais como grama, granito, tijolo e telha são originais do próprio trueSpace.

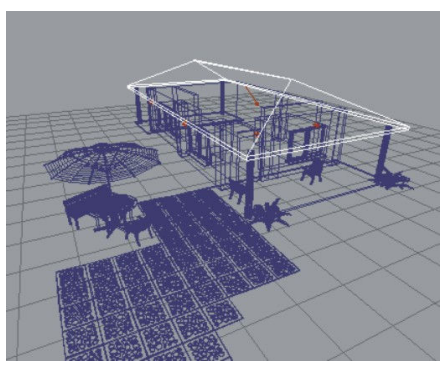

Figura 14. Criação da cena final. 
O fundo (figura 15) é uma imagem gerada no Terragen Classic, um gerador de terrenos fotorrealistas disponível gratuitamente na web. Para as árvores foi utilizada uma fotografia acompanhada de máscara obtida no site Exchange3d.com. As imagens foram montadas no TGA Tool, um utilitário feito especialmente para esse fim.

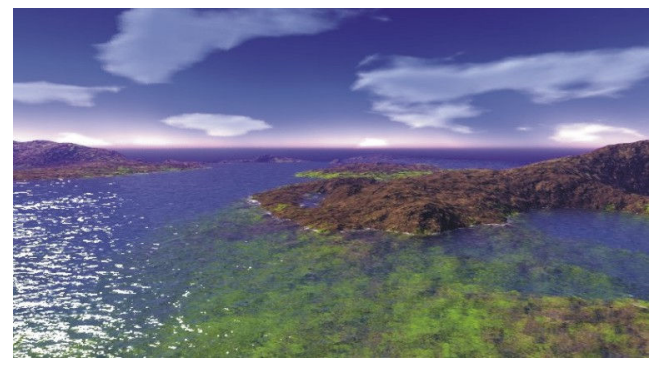

Figura 15. Imagem de fundo gerada no software Terragen Classic.

O resultado final é um arquivo TGA com canal alfa (transparência) que pôde então ser aplicado a três polígonos simples que, colocados de forma adequada na cena, proporcionaram uma imagem final bastante convincente (figura 16).

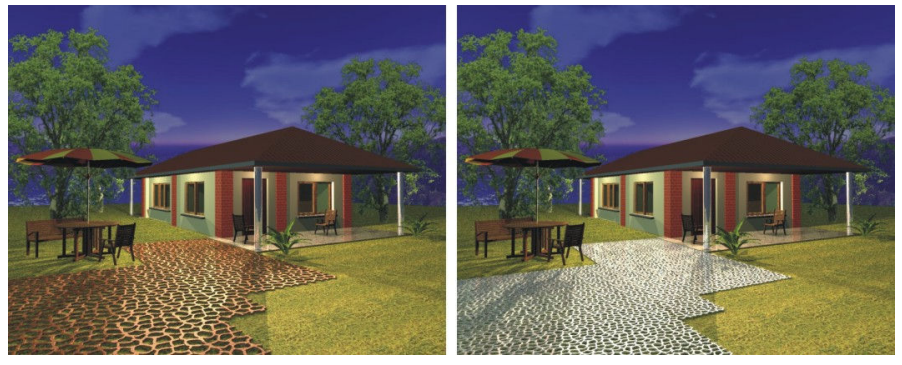

Figura 16. Cenas finais em 3D.

Os pisos foram então arranjados em conjuntos e exportados como objetos separados no trueSpace. A seguir eles foram importados na cena e renderizados em ray-tracing para a obtenção das imagens finais (figura 17).
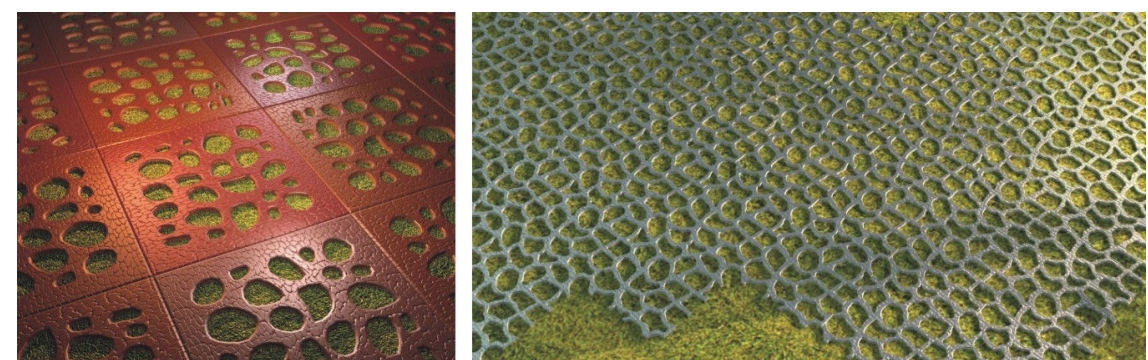

Figura 17. Pisos arranjados em conjunto e renderizados em ray-tracing. 


\section{Resultados e Discussões}

Através das simulações tridimensionais foi possível testar diferentes dimensionamentos e espessuras para os dois modelos de pisos propostos, o primeiro com borda e em material cerâmico e o segundo, contínuo, sem borda e em alumínio anodizado. A consideração inicial foi a respeito dos vazados internos em ambos os pisos. Mantendo as proporções entre a área externa e interna, quanto maior a área do piso, maiores ficariam os vazados e, conseqüentemente, menor seria a área de apoio para o usuário. Considerando inicialmente a utilização da cerâmica, verificou-se que os tamanhos das formas vazadas internas não poderiam ser muito grandes, pois poderia comprometer a resistência do piso além de dificultar o caminhar sobre o mesmo. Estimou-se então uma área total de $25 \times 25 \mathrm{~cm}$, medida padrão de pisos cerâmicos e normalmente adotada pela maioria das empresas. Além disso, acredita-se que a proporção dos vazados internos em relação a área total do piso se torna mais apropriada dentro dessa medida. Serão necessários testes para comprovar essa hipótese.

No entanto, a preocupação em relação a resistência do piso e a necessidade de diversificar e buscar novas opções de materiais que possam ser utilizados em pisos para áreas externas vislumbrou-se a possibilidade de fabricação deste piso em alumínio anodizado. O Alumínio anodizado é um alumínio de alta qualidade, extremamente leve e tratado termicamente para aumentar a tensão e resistência a corrosão. Essas características tornam o material apropriado ao uso a que se destina. Esse material permite também que se obtenha variações de cor da superfície, o que torna o piso mais versátil e agrega valor ao produto. Além disso, constatou-se que o alumínio não é um material comumente usado na fabricação de pisos para áreas externas. Segundo a $A B A L^{13}$ (Associação Brasileira do Alumínio), "a variedade de aplicações do alumínio está relacionada com suas características físico-químicas, com destaque para seu baixo peso específico comparado com outros metais de grande consumo, resistência à corrosão e alta condutibilidade elétrica e térmica".

Hipoteticamente, caso os dois pisos fossem produzidos em alumínio, foi feito um cálculo de custo para os mesmos. O volume do Piso 1 , se ele tiver $2,5 \mathrm{~cm}$ de altura, é de $925,70 \mathrm{~cm}^{3}$. O volume do Piso $2 \mathrm{com} 2,5 \mathrm{~cm}$ de altura é de $679,89 \mathrm{~cm}^{3}$. Como o alumínio de liga 356.0 possui uma massa específica de $2,69 \mathrm{~g} / \mathrm{cm}^{3}$, as massas dos pisos seriam de 2,490 $\mathrm{kg}$ para o piso 1 e de $1,830 \mathrm{~kg}$ para o piso 2 . Levando em consideração que o valor do quilograma do alumínio no mercado é de US\$2.00, ou aproximadamente RS 4,00, o custo de material por cada peça do piso 1 seria de $R \$ 9,96$ e o do piso 2 de $R \$ 7,32$. Ou seja, o valor por $\mathrm{m}^{2}$ seria de $\mathrm{R} \$ 39,84$ para o piso 1 e $\mathrm{R} \$ 29,28$ para o piso 2 .

Os modelos tridimensionais confirmam que os módulos do segundo modelo encaixam-se bem um ao outro no momento da replicação, gerando uma superfície contínua, o que caracteriza um rapport. Já o primeiro modelo é propositalmente apenas um módulo em repetição, sem continuidade entre uma peça e outra, para se ter uma maior área plana que suporte a aplicação de peso sem que o material cerâmico ceda. 
Acredita-se que de fato o piso contribuirá para a infiltração da água da chuva, uma vez que ele é vazado e permite que a água seja absorvida pelo solo ao invés de deslizar sobre o piso. Evita-se assim que a água se deposite sobre o piso, gerando uma superfície potencialmente perigosa por ser úmida e deslizante.

O padrão gerado a partir da fruta, além de ter sido aplicado nos módulos de forma vazada, também foi aplicado como textura antiderrapante em alto-relevo.

\section{Conclusão}

No estudo realizado verificou-se que a partir de um elemento natural utilizado como referência biônica é possível gerar novas formas e estruturas. A busca por referências na natureza auxiliou o processo criativo e possibilitou soluções visuais diversificadas.

Visando a aplicação dessas novas formas em revestimentos de superfície, fez-se necessário o levantamento do cenário atual desse segmento. Observou-se que, embora exista uma grande variação de modelos, texturas e formas de revestimentos, a idéia de pisos vazados para áreas externas pode ser mais explorada.

O desenvolvimento do projeto se deu através das etapas de digitalização tridimensional da fruta-do-conde, tratamento dos dados obtidos, testes em materiais, criação de textura, modelagem tridimensional dos pisos e renderização.

A forma do produto final apresentou textura similar à da fruta-do-conde, com pequenas adaptações estruturais. Ele contribui para a permeabilização do solo, permitindo a passagem de ar, luz e água da chuva, e evita o desvio do percurso natural da água.

Como sugestão para trabalhos futuros, pode-se aplicar a textura desenvolvida neste projeto em pisos para áreas internas, em paredes (para auxiliar no melhor aproveitamento da luz solar através dos vazados), tapetes, jogos infantis e na área moveleira, aliando a estética à funcionalidade. Outra sugestão para a continuidade deste projeto é a realização de testes de resistência e durabilidade no intuito de confirmar as hipóteses aqui lançadas.

\section{Referências}

BROECK, F. V. O uso de analogias biológicas. Revista Design e Interiores. São Paulo: n.15, p.97-100, 1989.

KINDLEIN JR, Wilson. GUANABARA, Andréa. Methodology for product design based on the study of bionics. Materials \& Design. Inglaterra, GB, v.26, n.2, p.149-155,apr.2005.

DOCZl, György. O Poder dos Limites: Harmonias e Proporções na Natureza, Arte e Arquitetura. São Paulo:Mercuryo, 1990. 
BONSIEPE, G. Diseño Industrial. Madri: Alberto Corazón Editor, 1978.

BIOMIMICRY INSTITUTE: Inspiring, educating and connecting biomimics throughout the world. Missoula, 2007-2010. Disponível em:

$<$ http://www.biomimicryinstitute.org/case-studies/casestudies/transportation.html> Acesso em: 22 set. 2010.

ROSSIN, K.J. Biomimicry: nature's design process versus the designer's process. In: BREBBIA, C.A.; CARPI, A. Design \& Nature V: Comparing Design in Nature with Science and Engineering. Southampton: WIT Press, 2010. P. 559-569.

MARTIUS, C.F.P. von. 1841. Annonaceae. In: C.F.P. von Martius (ed.). Flora Brasiliensis 13(1): 1-64. Disponível em:

<http://florabrasiliensis.cria.org.br/opus>

PEREIRA, Camila Ribeiro. Formação gastronômica do Cerrado - Estado de Goiás. 2008. 52 f. Monografia (Especialização em Gastronomia e Saúde) - Universidade de Brasília, Brasília, 2008. Disponível em: <http://bdm.bce.unb.br/handle/10483/313>

RÜTHSCHILLING, Evelise Anicet. Design de Superfície. Evelise Anicet Rüthschilling. Porto Alegre: Ed da UFRGS, 2008.

RUBIM, Renata. Desenhando a Superfície. Renata Rubim. São Paulo: Edições Rosari, 2004.

CARDOSO. Cilene Estol; RÜTHSCHILLING, Evelise Anicet; PERONDI, Eduardo. Design de Superfície em Revestimento Cerâmicos. In: Congresso Brasileiro de Pesquisa e Desenvolvimento em Design, $8^{\circ}$., 2008. Anais do $8^{\circ}$ Congresso Brasileiro de Pesquisa e Desenvolvimento em Design. São Paulo: AEND, 2008. p. 1580-1588.

EXPOREVESTIR: Feira Internacional de Revestimentos. [S.I.], 2009. Disponível em: <http://www.exporevestir.com.br/>

ABAL. Associação Brasileira do Alumínio. [S.I.], 1997. Disponível em: <http://www.abal.org.br/industria/historia.asp> 


\section{Ferramentas de Software Utilizadas}

ArtCAM: http://www.artcam.com/

CorelDRAW: http://www.corel.com.br/pt/

Geomagic: http://www.geomagic.com/

Inkscape 0.46: http://www.inkscape.org/

IrfanView 4.25: http://www.irfanview.com/

Terragen Classic 0.9.43: http://www.planetside.co.uk/content/view/16/28/

TGA tool 1.1: http://www.downloadatoz.com/multimedia-

design_directory/tga-tool/

trueSpace 3.2: http://www.caligari.com/

Wings3D 1.1.15: http://www.wings3d.com/

Xara Xtreme Pro 5: http://xara.com/us/products/xtreme/

\section{Web sites utilizados para download de modelos}

Exchange3d.com: http://www.exchange3d.com/

The3dStudio.com: http://www.the3dstudio.com/

trueSpace Community Forums:

http://forums1.caligari.com/truespace/index.php 